\title{
Dissociation of Psychomotor Sensitization from Compulsive Cocaine Consumption
}

\author{
Serge H Ahmed*', and Martine Cador' \\ 'Laboratoire de Neuropsychobiologie des Désadaptations, University Victor-Segalen Bordeaux2, Bordeaux, France
}

\begin{abstract}
The transition from drug use to drug addiction is associated with a process of escalation, whereby drug use becomes excessive and difficult to control. Several mechanisms have been advanced to explain escalating patterns of drug use as opposed to nonescalating patterns. Although current evidence favors hedonic tolerance, there remains some dispute about the contribution of behavioral sensitization to cocaine intake escalation. Here, we concurrently assessed the ability of cocaine to induce psychomotor sensitization and drug-seeking behavior in animals with I-h (short access or ShA) vs 6-h (long access or LgA) access to intravenous (i.v.) cocaine selfadministration. As expected, cocaine intake by LgA rats escalated over time and became excessive compared to cocaine intake by ShA rats, which remained low and stable. Despite escalated levels of cocaine consumption, however, LgA rats were not more sensitized to cocaine than ShA rats. The dose-effect function for cocaine-induced locomotion $(0.125-1 \mathrm{mg}$, i.v.) was shifted to the left in $\mathrm{LgA}$ rats by the same amount as in ShA rats after cocaine self-administration. In contrast, LgA rats were much more responsive than ShA rats to the motivational effects of cocaine, as measured by the ability of i.v. cocaine to reinstate extinguished drug-seeking behavior. This study demonstrates a dissociation of psychomotor sensitization from the change in motivation underlying the transition to compulsive cocaine consumption, and therefore suggests that responsiveness to the motivational effects of the drug, not psychomotor sensitization, would represent a specific behavioral marker of the transition to and maintenance of compulsive cocaine use.

Neuropsychopharmacology (2006) 31, 563-57I. doi: I0. 1038/sj.npp. I 300834; published online 20 July 2005
\end{abstract}

Keywords: addiction; abuse; self-administration; tolerance; sensitization; relapse

\section{INTRODUCTION}

A critical goal of drug addiction research is to understand the differences between controlled and compulsive drug use, the latter being diagnostic of addiction. Based on previous work using continuous access to drug selfadministration (Deneau et al, 1969; Johanson et al, 1976; Bozarth and Wise, 1985; Wolffgramm, 1991), we and others have recently developed and begun to validate an animal model of the transition to compulsive drug use (Ahmed and Koob, 1998; Mantsch et al, 2001; Paterson and Markou, 2003; Roth and Carroll, 2004; Vanderschuren and Everitt, 2004; Liu et al, 2005). Differential access to intravenous i.v. cocaine or heroin self-administration produces two patterns of drug intake. With $1 \mathrm{~h}$ of access per session (short access or ShA), drug intake is low and stable over time. In contrast, with 6 or more hours of access per session (long access or LgA), drug intake gradually escalates and becomes excessive

\footnotetext{
*Correspondence: Dr SH Ahmed, Laboratoire de Neuropsychobiologie des Désadaptations, CNRS-UMR 554I, University Victor-Segalen Bordeaux2, 146 rue Léo-Saignat, Bordeaux 33076, France, Tel: + 33 557 57। 566, Fax: + 33556900 278,

E-mail: sahmed@Inpb.u-bordeaux2.fr

Received 10 March 2005; revised 17 May 2005; accepted 3 June 2005 Online publication: 20 June 2005 at http://www.acnp.org/citations/ Npp062005050 174/default.pdf
}

compared to control levels (Ahmed and Koob, 1998; Ahmed et al, 2000). Once established, escalated levels of drug consumption can persist several weeks, despite reduced drug availability (Ahmed and Koob, 1999).

The differences between stable and escalating patterns of drug consumption has been proposed to model the differences drawn by clinicians between controlled and compulsive drug use (Ahmed and Koob, 1998). This interpretation is supported by a recent series of studies showing that rats with escalated levels of drug intake (LgA rats) can be considered as genuine drug-addicted individuals compared to rats with stable drug intake (ShA rats). First, LgA rats persist more than ShA rats in seeking the drug despite the fact that their behavior is no longer rewarded (Ahmed et al, 2000). Second, LgA rats show an increased motivation to work to obtain the drug compared to ShA rats, as measured under a progressive ratio schedule of drug self-administration (Paterson and Markou, 2003; Lenoir and Ahmed, unpublished results; but see, Liu et al, 2005). Third, when foraging for the drug, LgA rats ignore signals of potential dangers and thus take increased risks to obtain the drug (Vanderschuren and Everitt, 2004). Finally, LgA rats tend to be more sensitive than ShA rats to drug- and stress-induced relapse during forced abstinence (Ahmed et al, 2000; Mantsch et al, 2004), as measured in the now classical reinstatement model of 
drug relapse (Shaham et al, 2003; See et al, 2003; Weiss et al, 2001).

Several different mechanisms can be advanced to explain the transition to and maintenance of escalated drug use in animals with extended access to the drug, including tolerance to the suppressive effects of the drug (Zernig et al, 2004), sensitization to its psychomotor effects (Robinson and Berridge, 1993), or reward allostasis-induced tolerance to its rewarding effects (Koob and Le Moal, 2001). Although current evidence favors a role for reward allostasis (Ahmed et al, 2002, 2003; Ahmed and Koob, 2005; Barrett et al, 2004), there remains some dispute concerning the contribution of psychomotor sensitization to cocaine intake escalation (see Zernig et al, 2004 and associated commentaries). Psychomotor effects have been hypothesized to be homologous to either the rewarding effects of the drug (Wise and Bozarth, 1987) or to its incentive effects (Robinson and Berridge, 1993). According to the sensitization hypothesis, LgA rats should sensitize more to the psychomotor effects of cocaine during escalation than ShA rats. In a previous study, however, LgA rats were shown not to be more sensitive than ShA rats to the behavioral and neural effects of cocaine when tested shortly (3 days) after escalation of cocaine self-administration (Ben-Shahar et al, 2004). This result suggests that the transition to and maintenance of escalated levels of cocaine self-administration are not associated with an increased efficacy of the drug, a finding consistent with recent neurophysiological and neurochemical findings (Ahmed et al, 2002, 2003; Barrett et al, 2004).

The present study is a follow-up study designed to reproduce and extend these previous findings in several different ways. First, animals were tested with a relatively large range of cocaine doses $(0.125-1 \mathrm{mg}$, i.v.) to generate a dose-effect function for cocaine-induced locomotion before and at different times during the transition to and maintenance of escalated levels of cocaine self-administration. This procedure allowed both within- and betweensubjects assessments of psychomotor sensitization. Second, the stimulant effects of cocaine were measured in the environment paired with cocaine self-administration, thereby preserving the well-documented environmental specificity of psychomotor sensitization (Tilson and Rech, 1973; Stewart and Vezina, 1991; Ahmed et al, 1993). Finally, we compared the efficacy of cocaine to induce concurrently locomotion and reinstatement of drug-seeking behavior during the maintenance of escalated levels of cocaine selfadministration. This experimental design uniquely allowed us to study how the psychomotor (locomotion), motivational (reinstatement of drug-seeking behavior), and rewarding (self-administration) effects of cocaine are differentially altered during the transition to and maintenance of escalated cocaine consumption.

\section{MATERIALS AND METHODS}

\section{Subjects}

In all, 27 naïve, male, Wistar rats were used, weighing 225$282 \mathrm{~g}$ prior to surgery (Charles River, Germany). Rats were housed in groups of two or three and were maintained in a light- (12-h light-dark cycle; lights on at 0900) and temperature-controlled vivarium $\left(23^{\circ} \mathrm{C}\right)$. All behavioral testing occurred during the dark phase of the light-dark cycle. Food and water were freely available, except during operant food training. All experiments were carried out in strict accordance with institutional and international standards of care and use of laboratory animals (UK Animals (Scientific Procedures) Act, 1986; and associated guidelines; the European Communities Council Directive (86/609/EEC, 24 November 1986) and the French Directives concerning the use of laboratory animals (décret 87-848, 19 October 1987).

\section{Apparatus}

In all, 12 identical operant chambers $(30 \times 40 \times 36 \mathrm{~cm})$ were used for all behavioral training and testing (Imétronic, France). All chambers were located away from the colony room in a dimly lit room with a background white noise. They were individually enclosed in wooden cubicles equipped with an exhaust fan for ventilation and sound attenuation. Each chamber had a stainless-steel grid floor (rod diameter: $6 \mathrm{~mm}$; inter-rod distance: $16 \mathrm{~mm}$ ) and was constituted of two opaque operant panels on the right and left sides, and two clear Plexiglas walls on the back and front sides. One retractable lever (Imétronic, France) was mounted $6.5 \mathrm{~cm}$ above the grid floor on the left operant panel and protruded from the wall $1 \mathrm{~cm}$ (when extended). A white light bulb $(1.8 \mathrm{~cm}$ OD) was mounted $8.5 \mathrm{~cm}$ above the lever (from the center of the bulb). The lever controlled a syringe pump (Razel, Bioblock scientific, France) mounted on the top of the cubicle. Drug solution was delivered through a Tygon tubing (Cole Parmer Instrument Company, Illinois, USA) via a single-channel liquid swivel (Lomir Biomedical Inc., Canada) to a cannula connector (Plastics One, Roanoke, VA, USA) on the back's of the animal. The Tygon tubing was protected by a stainless steelspring (3.1 mm ID; $4.8 \mathrm{~mm}$ OD) (Aquitaine Ressort, France), which was suspended at the center of the chamber from the swivel tether connector. Vertical movements of the animal were damped out by means of a counterbalancing weightpulley device (Imétronic, France).

Each self-administration chamber was also equipped with two couples of infrared beams $2 \mathrm{~cm}$ above the grid floor. Both couples crossed the chamber on its length axis (Imétronic, France) and were separated from each other by about $17 \mathrm{~cm}$, and from the right or left wall by about $11.5 \mathrm{~cm}$. This repartition allowed one to count the number of horizontal displacements of the animal to go to and fro between the two extremities of the length axis (cage crossings or crossovers). Operant chambers were connected to a PC via an Imétronic interface and experiments were controlled and programmed using an Imétronic software (Imétronic, France).

\section{Catheter Surgery}

Anesthetized rats (Chloral hydrate, $500 \mathrm{mg} / \mathrm{kg}$ intrapenitoneally (i.p.) (J-T Baker, The Netherlands) were prepared with silastic catheters (Dow Corning Corporation, Michigan, USA) in the right jugular vein that exited the skin in the middle of the back about $2 \mathrm{~cm}$ below the scapulae (Caine et al, 1993). After surgery, catheters were flushed daily with 
$0.15 \mathrm{ml}$ of a sterile antibiotic solution containing heparinized saline $(280 \mathrm{IU} / \mathrm{ml})$ (Sanofi-Synthelabo, France) and ampicilline (Panpharma, France). When needed, the patency of the catheter was checked by administering $0.15 \mathrm{ml}$ of the short-acting nonbarbiturate anesthetic etomidate through the catheter (Braun Medical, France).

\section{I.v. Cocaine Self-Administration}

After i.v. catheterization (1 week), rats were food restricted (85\% of their free-feeding body weight) and trained to press a lever for $45-\mathrm{mg}$ food pellets on a fixed ratio 1 (final time out $=20 \mathrm{~s}$ ) schedule during six daily sessions (Ahmed and Koob, 1997). Training sessions lasted $1 \mathrm{~h}$ or until 100 pellets were delivered, whichever came first. Food restriction was terminated and 1 week later, rats were tested for cocaine self-administration during two consecutive phases: a screening phase (one session) and an escalation phase (36 sessions). During the screening phase, rats were allowed to self-administer cocaine $(0.25 \mathrm{mg}$ per unit dose delivered in $2 \mathrm{~s}$ ) during only $1 \mathrm{~h}$ after which two balanced groups with the same mean body weight (ShA rats, $371 \pm 5 \mathrm{~g}$; LgA rats, $366 \pm 7 \mathrm{~g}$ ) and mean cocaine self-administration (ShA rats, $18.6 \pm 3.1$ injections; LgA rats, $17.6 \pm 3.3$ injections) were formed. This 1-day screening method of balancing groups was shown to be highly reliable in previous experiments on escalation of cocaine (Ahmed et al, 2002, 2003, 2005) or heroin self-administration (Ahmed and Lenoir, in preparation). During the escalation phase, one group had access to cocaine self-administration for only $1 \mathrm{~h}$ per day (ShA rats, $n=15$ ) and the other group for $6 \mathrm{~h}$ per day (LgA rats, $n=12)$.

All self-administration sessions began with extension of the lever. The first response on the lever triggered the countdown to the session ending. Subsequent responding on the lever resulted in the delivery of one unit dose of cocaine and initiated a 20-s time-out period signalled by the light cue located above the lever. No noncontingent injections of cocaine were given, except on rare occasions when a subject failed to respond within the first $10 \mathrm{~min}$ in which case it received two passive injections $20 \mathrm{~s}$ apart. No inactive lever was used in the present study; under our conditions, inactive responses are negligible during cocaine self-administration and are unaffected during escalation (Ahmed and Koob, 1997, 1998). Self-administration sessions were run 4-6 days per week.

\section{Cocaine-Induced Psychomotor Stimulation}

The psychomotor effects of cocaine were assessed on three occasions in the self-administration chamber: $24 \mathrm{~h}$ before any exposure to cocaine self-administration (test 0 ) and $24 \mathrm{~h}$ after sessions 20 and 24 of the escalation phase (tests 20 and 24), when the mean number of cocaine injections had leveled off in ShA rats (Figure 1). Note also that the short withdrawal period $(24 \mathrm{~h})$ allowed us to probe the subject's sensitivity to the psychomotor effects of cocaine at different times during the transition to and maintenance of escalated levels of cocaine intake. Between tests 20 and 24, rats continued to self-administer cocaine 1 or $6 \mathrm{~h}$ during 4 consecutive days. During each test, the lever was retracted. After $45 \mathrm{~min}$ of habituation, rats received five doses of
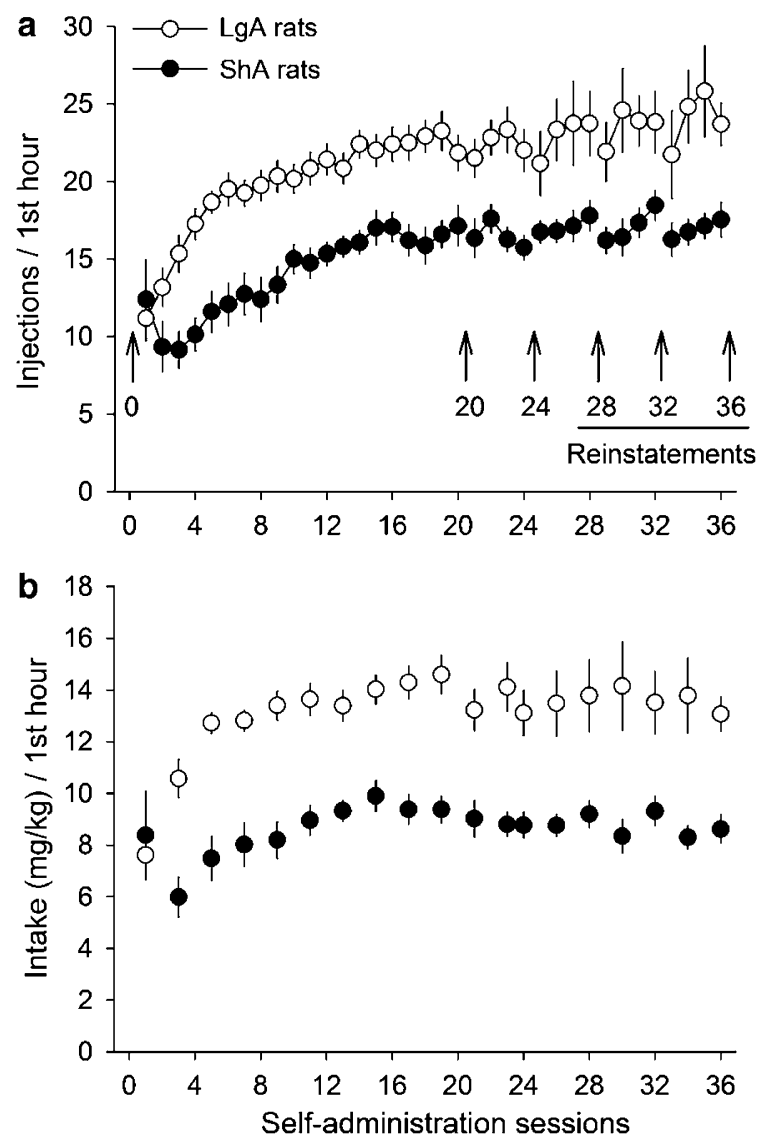

Figure I Effects of access time to cocaine self-administration on the number of cocaine injections (a) and on cocaine intake (b) during the first hour (means \pm SEM). Rats had access to cocaine $(0.25 \mathrm{mg} /$ injection) for either I $h$ (ShA rats, $n=15$ ) or $6 \mathrm{~h}$ per day (LgA rats, $n=12$ ). All rats were also tested for cocaine-induced stimulation of locomotion and/or reinstatement of drug-seeking behavior before (test 0 ) and at different times after cocaine self-administration (ie $24 \mathrm{~h}$ after self-administration sessions 20, 24, 28, 32, and 36), as indicated by vertical arrows. Rats continued to self-administer cocaine ( 1 or $6 \mathrm{~h}$ ) between each test. Note that rats were weighed every other sessions which explains why there are less data points in (b) than in (a).

cocaine $(0,0.125,0.25,0.5$, and $1 \mathrm{mg})$ every $45 \mathrm{~min}$ by increasing the duration of the injection $(0,1,2,4$, and $8 \mathrm{~s})$. Note that the highest dose tested that corresponds to about $2.4 \mathrm{mg} / \mathrm{kg}$ during tests 20 and 24 is near the convulsant dose (ie $2 \mathrm{mg}$ or $4.8 \mathrm{mg} / \mathrm{kg}$ ) in our experimental conditions. Each dose delivery was signalled by turning on for $20 \mathrm{~s}$ the light cue located above the insertion site of the lever. Crossovers were counted over $45 \mathrm{~min}$ after each dose delivery.

\section{Cocaine-Induced Reinstatement of Drug-Seeking Behavior}

Cocaine-induced reinstatement of extinguished drug-seeking behavior were assessed on three occasions in the selfadministration chamber: $24 \mathrm{~h}$ after sessions 28,32 , and 36 of the escalation phase (tests 28,32, and 36) (see Figure 1). Note that this short withdrawal period $(24 \mathrm{~h})$ allowed us to probe the subject's sensitivity to the motivational effects of cocaine at different times during the maintenance of 
escalated levels of cocaine intake. Between reinstatement tests, rats continued to self-administer cocaine ( 1 or $6 \mathrm{~h})$ during 4 consecutive days. During each reinstatement test, the lever was extended but lever pressing had no programmed consequence (no contingent drug injection or light cue presentation), thereby inducing a rapid withinsession extinction of cocaine-seeking behavior. Note that no contingent light cue was available during reinstatement testing because stimulant drugs can dramatically increase operant responding for discrete light changes in naïve rats (Berlyne, 1969; Gomer and Jakubczak, 1974). After 45 min of extinction, rats received five doses of cocaine, as described above. Both cocaine-induced drug-seeking behavior (ie nonreinforced lever pressing) and locomotion (crossovers) were counted over $45 \mathrm{~min}$ after each dose.

\section{Drugs}

Cocaine hydrochloride (Coopération Pharmaceutique Française, France) was dissolved in $500-\mathrm{ml}$ sterile bags of $0.9 \% \mathrm{NaCl}$ and kept at room temperature $\left(21 \pm 2^{\circ} \mathrm{C}\right)$. Cocaine doses were expressed as the weight of the salt.

\section{Data Analysis}

Behavioral data were subjected to two- or three-way analyses of variance with one between-subjects factor (experimental groups: ShA and LgA groups) and one or two within-subjects factor (self-administration sessions, tests, cocaine doses, or time intervals). All post hoc comparisons for interactions were carried out by the Newman-Keuls test. Two LgA rats died of overdose, one during session 31 and the other during session 36. As a result, the $N$ for the LgA group was 11 and 10 during the second and third reinstatement tests, respectively.

\section{RESULTS}

\section{Escalation of Cocaine Self-Administration}

To compare appropriately cocaine self-administration in rats with different access time to cocaine ( $1 v s 6 \mathrm{~h}$ ), only the number of cocaine injections earned during the first hour was compared between ShA and LgA rats (Figure 1). Note that the first session in Figure 1 corresponds to the first day with differential access to cocaine self-administration ( 1 vs $6 \mathrm{~h}$ ), and not to the screening day. The number of cocaine injections was similar in both groups during the first session of the escalation phase (Group: $F(1,25)=0.15$ ) (Figure 1). During the escalation phase, however, cocaine injections in LgA rats significantly increased above the level of ShA rats (Group: $\mathrm{F}(1,25)=24.53, p<0.05)$. Total intake by $\operatorname{LgA}$ rats also increased from a mean of $59.3 \pm 4.2$ to $112.1 \pm 7.5$ injections (not shown). Similar results were obtained when cocaine intake was normalized to the weight of individual rats (Group: $\mathrm{F}(1,25)=40.53, p<0.05$; Group $\times$ Session: $F(18,450)=2.18, p<0.05) \quad($ Figure $1 b)$. Note that rats were weighed every other sessions which explains why there are less data points in Figure $1 \mathrm{~b}$ than in Figure 1a.

\section{Cocaine-Induced Psychomotor Stimulation}

As expected, i.v. cocaine produced a dose-dependent increase in forward locomotion (Figure $2 \mathrm{a}$ and $\mathrm{b}$ ). This dose-effect function was shifted to the left after exposure to cocaine self-administration (Dose $\times$ Session: $F(8,200)=$ 5.27, $p<0.05)$ with no significant difference between groups. Post hoc tests revealed that $\mathrm{ShA}$ and $\operatorname{LgA}$ rats responded more to 0.25 and $0.5 \mathrm{mg}$ of cocaine after drug self-administration (test $0 v s$ test 20: $p$ 's $<0.05$; test $0 v s$ test 24: $p$ 's $<0.05$; Newman-Keuls test). To assess the relationship between psychomotor sensitization and cocaine self-administration, we computed for each individual a global sensitization score as follows: the totals of crossovers induced by 0.25 and $0.5 \mathrm{mg}$ of cocaine were averaged across tests 20 and 24 and the result was diminished by the total obtained during test 0 . In ShA rats, the sensitization score was negatively correlated with stabilized cocaine self-administration, as averaged across self-administration sessions $16-24 \quad(r=-0.69$, $p<0.05$ ) (Figure 3a). Similar results were obtained in $\operatorname{LgA}$ rats, but they were not statistically significant $(r=-0.51$, NS) (Figure $3 b$ ).

LgA rats gained less weight than ShA rats during escalation of cocaine intake, a phenomenon that reproduces previous findings (see Table 1 in Ahmed and Koob, 1999). As a result, during post-escalation cocaine tests, LgA rats were on average $11 \%$ lighter than ShA rats. Theoretically, this small difference in body weight between the two groups should result in different brain cocaine levels following administration of the same absolute doses. Previous empirical studies have shown, however, that this was not the case (Ahmed et al, 2003). Absolute doses of cocaine similar to those used in the present study (ie $0.125,0.25$, and $1 \mathrm{mg}$, i.v.) resulted in the same increases in brain cocaine concentrations in both ShA and LgA rats (Ahmed et al, 2003). Nevertheless, to circumvent this potential bias, we normalized cocaine doses to the actual mean body weight of

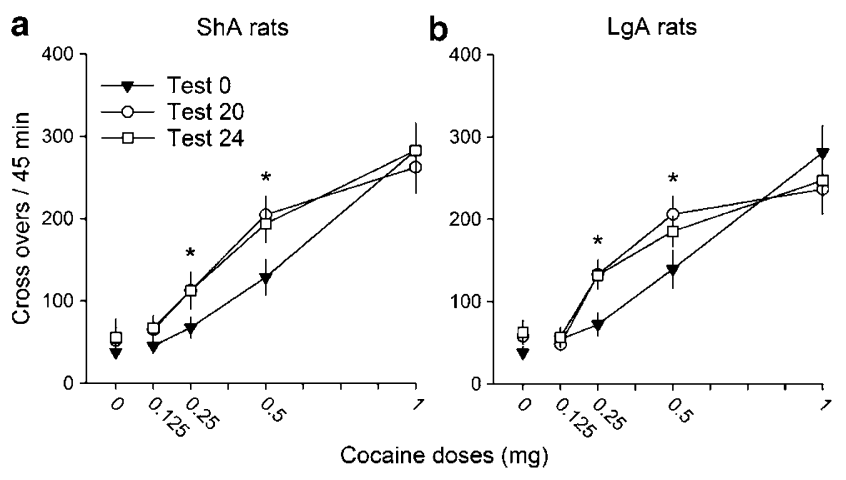

Figure 2 Effects of access time to cocaine self-administration on cocaine-induced stimulation of locomotion (means \pm SEM). The psychomotor effects of cocaine were assessed on three occasions in both ShA (a) and $\mathrm{LgA}$ rats (b): $24 \mathrm{~h}$ before any exposure to cocaine self-administration (test 0 ) and $24 \mathrm{~h}$ after self-administration sessions 20 and 24 (tests 20 and 24). During all tests, rats passively received increasing i.v. doses of cocaine, one dose every $45 \mathrm{~min}$ with the first 45 -min interval corresponding to behavioral habituation. Behavioral testing took place in the self-administration chamber $(40 \mathrm{~cm}$ in length). Note that during psychomotor testing, the lever was retracted. *Different from test 0 ( $p<0.05$, Newman-Keuls test). 

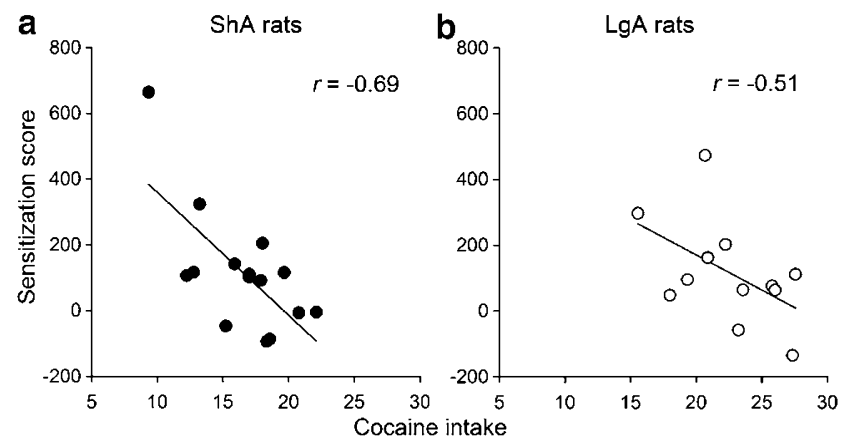

Figure 3 Relationship between psychomotor sensitization and maintained cocaine self-administration in ShA (a) and LgA rats (b). The sensitization score corresponds to the total increase in cocaine-induced locomotion produced by the doses of 0.25 and $0.5 \mathrm{mg}$ after cocaine selfadministration. Cocaine intake corresponds to the average number of injections across self-administration sessions 16-24.

each group during tests 20 and 24 . We then estimated the $\mathrm{ED}_{50}$ for cocaine-induced locomotion by fitting the data of each group with the classical sigmoid $E_{\max }$-model (Meibohm and Derendorf, 1997), which accounted for more than $75 \%$ of the data variance. The results show that the estimated $\mathrm{ED}_{50}$ for cocaine-induced psychomotor stimulation was similar in both groups of rats during test 20 (ShA rats, $0.8 \mathrm{mg} / \mathrm{kg}$; LgA rats, $0.7 \mathrm{mg} / \mathrm{kg}$ ) and test 24 (ShA rats, $1.1 \mathrm{mg} / \mathrm{kg}$; $\mathrm{LgA}$ rats, $0.9 \mathrm{mg} / \mathrm{kg}$ ).

To assess the potential contribution of motor stereotypies to the locomotion data, the time course of the psychomotor effects of cocaine was analyzed with a temporal resolution of $3 \mathrm{~min}$. Generally, motor stereotypies produce an early inhibition of locomotion followed by a rebound increase, thereby resulting in a biphasic time course of behavioral stimulation (eg Kuczenski et al, 1997). As shown in Figure 4, however, there was no reliable evidence for an early inhibition of locomotion with the range of doses tested. More importantly, we did not detect any significant difference between ShA and LgA rats in the time course of cocaine-induced locomotion, regardless of the dose tested and time intervals (Figure 4).

\section{Cocaine-Induced Reinstatement of Drug-Seeking Behavior}

During the first reinstatement test (test 28), LgA rats responded more on the drug lever than ShA rats, a difference that was dose dependent (Group: $F(1,25)=$ 8.37, $p<0.05 ;$ Group $\times$ Dose: $\mathrm{F}(4,100)=6.15, \quad p<0.05)$ (Figure 5a). The same observation was made during the second (test 32: Group: $\mathrm{F}(1,24)=12.27, p<0.05$; GroupDose: $F(4,96)=4.71, p<0.05$ ) (Figure $5 c$ ) and third reinstatement test (test 36: Group: $\mathrm{F}(1,23)=10.63$, $p<0.05 ; \quad$ Group $\times$ Dose: $\quad \mathrm{F}(4,92)=10.51, \quad p<0.05)$ (Figure 5e). Post hoc comparisons revealed that LgA rats responded more to cocaine than ShA rats at the doses of $0.25,0.5$, and $1 \mathrm{mg}$ during tests 28,32 , and 36 ( $p$ 's $<0.05$, Newman-Keuls test). In contrast, during all reinstatement tests, LgA rats were as sensitive as ShA rats to the psychomotor effects of cocaine (Figure $5 b, d$, and $f$ ),
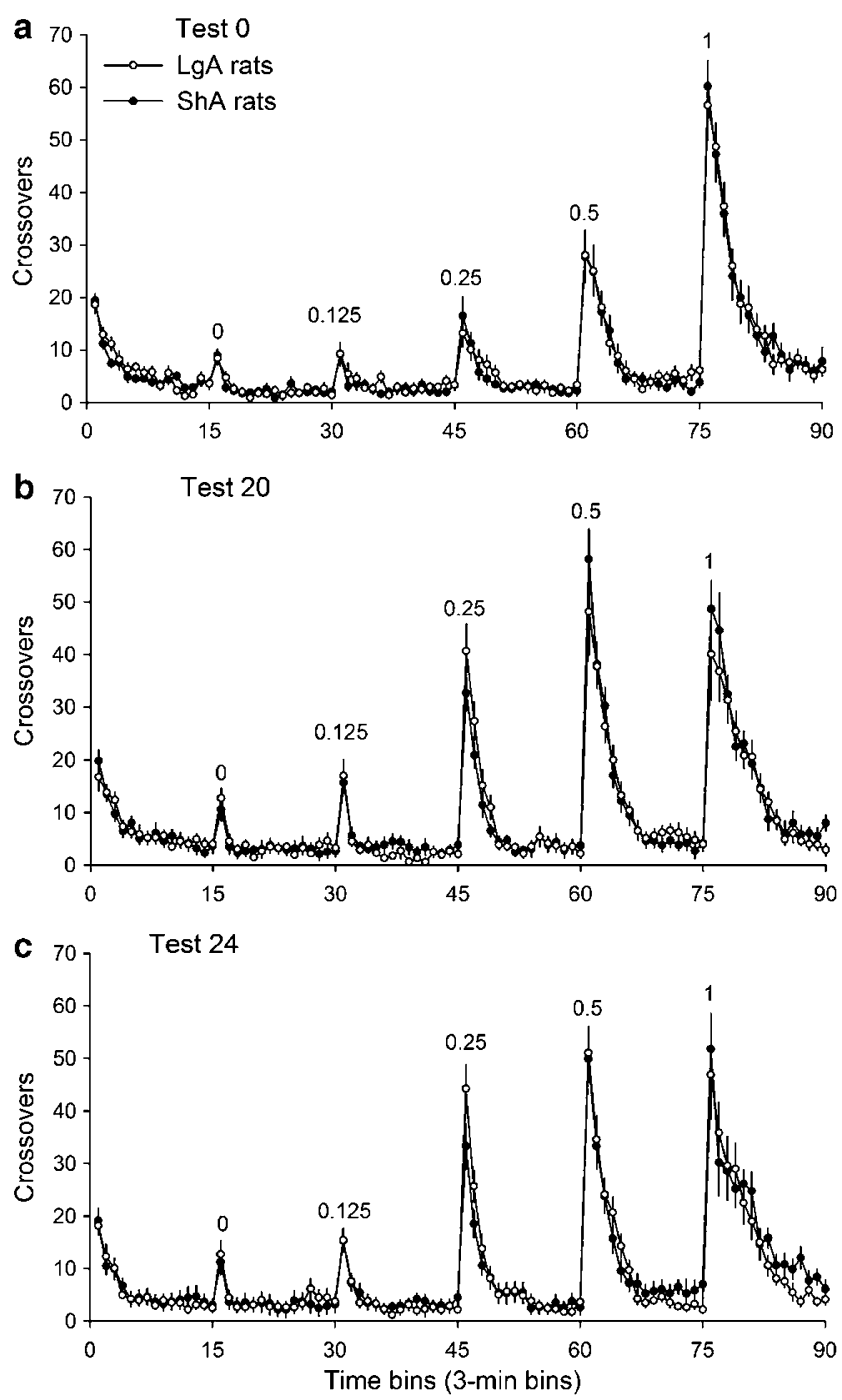

Figure 4 Time course of cocaine-induced locomotion (means \pm SEM). The psychomotor effects of cocaine were assessed on three occasions: $24 \mathrm{~h}$ before any exposure to cocaine self-administration (a) and $24 \mathrm{~h}$ after self-administration sessions 20 (b) and 24 (c). For other details, see the legend of Figure 2.

suggesting a dissociation between the psychomotor and motivational effects of cocaine. Note that identical findings were obtained when only the first $10 \mathrm{~min}$ postinjections were considered for analysis (not shown). Importantly, during all reinstatement tests, the proportion of LgA individuals that responded to cocaine was greater than the proportion of ShA rats $\left(\chi^{2}=109.13\right.$, d.d.l. $\left.=2, p<0.05\right)$ (Figure 6a). An individual was considered as a cocaine responder during reinstatement testing if its level of responding at the highest dose was above its level at the dose 0 by at least $1 \mathrm{SD}$ of the mean at the dose 0 (test 28: $1 \mathrm{SD}=24.0$ responses; test $32: 1 \mathrm{SD}=10.4$ responses; test 36 : $1 \mathrm{SD}=11.0$ responses). Also, the percentage of rats that responded to cocaine at least two times across all three tests was much greater in the LgA group (75\%) than in the ShA group (20\%) (Figure 6b).

These results show that escalated cocaine intake is associated with an increased responsiveness to the motiva- 
a
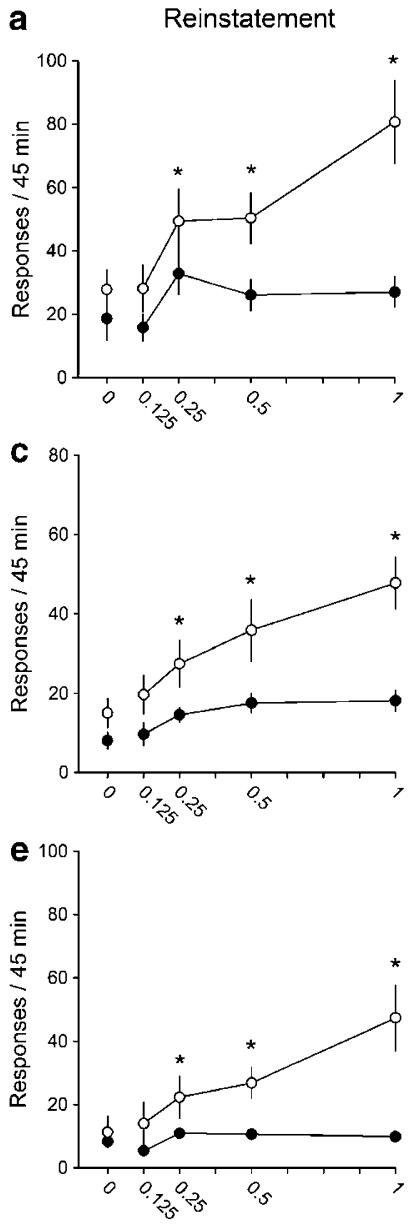

Cocaine doses $(\mathrm{mg})$
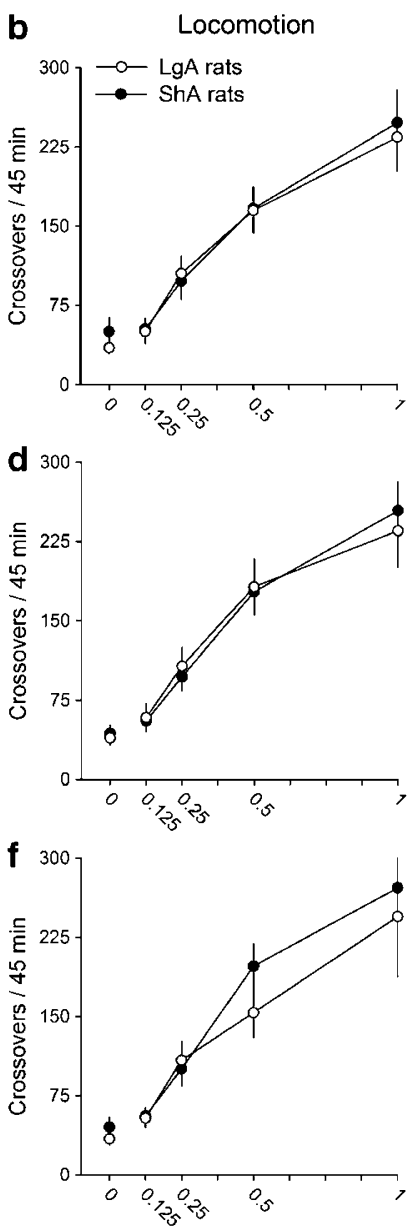

Figure 5 Cocaine-induced reinstatement of extinguished drug-seeking behavior and stimulation of locomotion (means \pm SEM). The motivational (right panels) and psychomotor (left panels) effects of cocaine were concurrently assessed on three occasions: $24 \mathrm{~h}$ after self-administration sessions 28 ( $a$ and b), 32 ( $c$ and d), and 36 (e and f). During all tests, rats passively received increasing i.v. doses of cocaine, one dose every $45 \mathrm{~min}$ with the first 45-min interval corresponding to behavioral extinction. During reinstatement testing, the lever was extended but lever pressing had no programmed consequence (no contingent drug delivery or light cue presentation). *Different from ShA rats $(p<0.05$, Newman-Keuls test)

tional effects of the drug but not to its psychomotor effects. To assess the persistence of this phenomenon, a large subset of rats (12 ShA rats and $10 \mathrm{LgA}$ rats) was allowed to continue to self-administer cocaine during eight additional 1- or 6-h sessions (ie until session 44), after which they were withdrawn during 14 days before being tested for both cocaine-induced locomotion and reinstatement (Figure 7). As during early withdrawal, during late withdrawal, LgA rats were not more sensitive than ShA rats to the psychomotor effects of cocaine (Figure $7 \mathrm{~b}$ ). In contrast, they were more responsive than ShA rats to the motivational effects of the drug (Group $\times$ Dose: $F(4,80)=2.79$, $p<0.05$ ) (Figure 7a). Post hoc comparisons revealed that LgA rats responded more than ShA rats to the motivational effects of cocaine at the doses of 0.5 and $1 \mathrm{mg}$ ( $p$ 's $<0.05$, Newman-Keuls test).
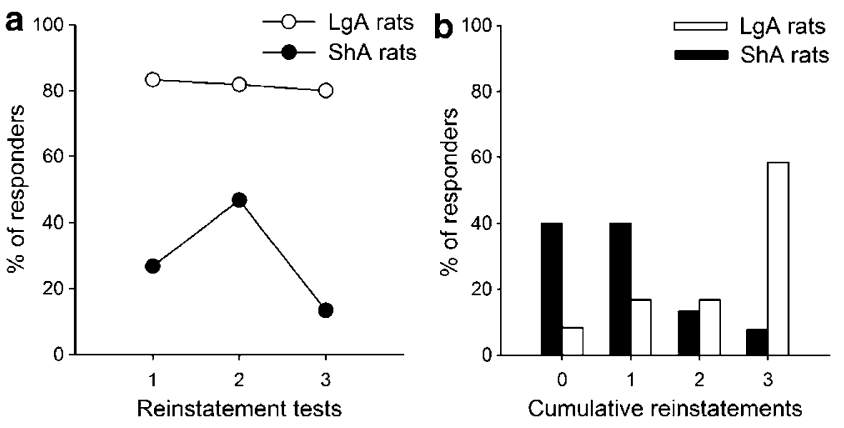

Figure 6 Percentage of rats that responded to cocaine during each reinstatement test (a) and percentage of rats that responded to cocaine 0 , I, 2, or 3 times across all three tests (b). An individual was considered as a cocaine responder during reinstatement testing if its level of responding at the highest dose ( I mg) was above its level at the dose 0 by at least I SD of the mean at the dose 0 .
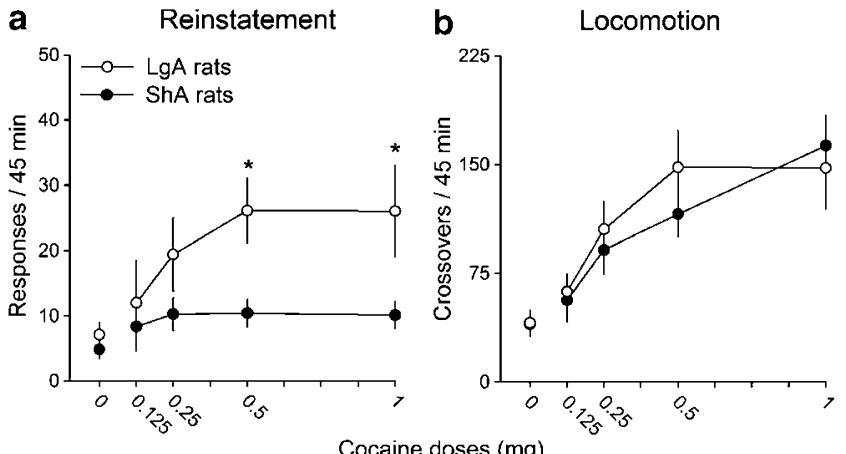

Figure 7 Cocaine-induced reinstatement of extinguished drug-seeking behavior (a) and stimulation of locomotion (b) after 2 weeks of withdrawal from 44 sessions of cocaine self-administration (means \pm SEM). For additional information, see the legend of Figure 5. *Different from ShA rats $(p<0.05$, Newman-Keuls test).

\section{DISCUSSION}

The present study shows that both nonescalated and escalated cocaine self-administration produced a robust psychomotor sensitization, as measured by a shift to the left of the dose-effect function for cocaine-induced locomotion. Interestingly, although fully sensitized and despite having a long experience with cocaine self-administration, the majority of rats with nonescalated levels of cocaine intake (ShA rats) were not responsive to the motivational effects of cocaine, as measured in a within-session reinstatement procedure. In contrast, most of the rats with escalated levels of cocaine self-administration (LgA rats) showed a dramatic responsiveness to the motivational effects of cocaine. These observations demonstrate a marked dissociation of psychomotor sensitization from the change in motivation underlying the transition to and maintenance of compulsive cocaine consumption. Also, these findings indicate that responsiveness to the motivational effects of cocaine, but not psychomotor sensitization, may represent a specific behavioral marker of the transition to compulsive cocaine use, as suggested previously (Sutton et al, 2000). 
In ShA rats, i.v. cocaine self-administration produced a robust psychomotor sensitization, a finding that reproduces previous observations in rats (Hooks et al, 1994; Phillips and Di Ciano, 1996; Sutton et al, 2000; Ben-Shahar et al, 2004) and mice (Zapata et al, 2003). In addition, the present study shows that psychomotor sensitization manifested as a shift to the left of the dose-effect function for cocaineinduced locomotion, without apparent change in the maximum effect of the drug. The magnitude of behavioral sensitization in ShA rats was negatively correlated with nonescalated levels of cocaine self-administration: the lower the sensitization, the higher the level of cocaine consumption $(r=-0.69)$. Although this finding needs to be reproduced, it may suggest that in animals with restricted access to the drug, psychomotor sensitization is more of a marker of low cocaine consumption than a marker of high cocaine consumption, contrary to what can be predicted from the sensitization hypothesis of drug addiction (see also, O’Brien, 2001).

This interpretation is strengthened by comparing psychomotor sensitization in ShA rats and LgA rats. With extended access to cocaine self-administration, $\operatorname{LgA}$ rats escalated their intake of cocaine above the level of cocaine intake by ShA rats, a phenomenon that reproduces previous findings (Ahmed and Koob, 1998; Roth and Carroll, 2004; Mantsch et al, 2001; Paterson and Markou, 2003; Liu et al, 2005). Escalated cocaine self-administration was not associated, however, with an increase in psychomotor sensitization. The dose-effect function for cocaine-induced stimulation of locomotion was shifted to the left in LgA rats by the same amount as in ShA rats after cocaine selfadministration. Thus, contrary to what can be predicted from the psychomotor sensitization hypothesis, rats with escalated cocaine use are not more sensitized to the psychomotor effects of cocaine than ShA rats. This conclusion is consistent with a previous neurochemical investigation showing that the dose-effect function for cocaine-induced dopamine in the nucleus accumbens was virtually identical between ShA and LgA rats (Ahmed et al, 2003).

There was also no evidence for cocaine-induced motor stereotypies in the present study. Motor stereotypies are generally induced at very high doses of stimulant drugs and mostly involve repetitive movements of the head and forepaws with the whole body relatively immobile (Lyon and Robbins, 1975). As a result, drug-induced stereotyped behaviors are associated with a biphasic temporal profile of locomotion, with an initial decrease in locomotion followed by a rebound increase (eg Kuczenski et al, 1997). Regardless of the group, this biphasic temporal profile was not observed in the present study, suggesting that the cocaine doses tested were probably not sufficient to induce significant levels of stereotypies. It should also be pointed out that drug-induced stereotyped behaviors are generally called upon to explain differences in drug-induced locomotion. The fact that no difference in cocaine-induced locomotion was observed between ShA and LgA rats suggests that group differences in stereotyped behaviors, if any, should be small in the present study.

The lack of difference in cocaine-induced locomotion between ShA and LgA rats seems to conflict with a previous study where LgA rats were shown to be less sensitized to cocaine than ShA rats (Ben-Shahar et al, 2004). At least one different procedural variable may explain the different outcomes between these two studies. In the present study, rats were tested for psychomotor sensitization in the selfadministration environment, while in the previous study, rats were tested in a different environment never paired with cocaine effects. Since psychomotor sensitization is exquisitely sensitive to the environmental context (Tilson and Rech, 1973; Stewart and Vezina, 1991; Ahmed et al, 1993), the different outcome between the two studies may suggest that psychomotor sensitization to cocaine in $\operatorname{LgA}$ rats is more sensitive to contextual shifts than in ShA rats. Future experiments are needed to test this hypothesis.

Together with previous findings (Sutton et al, 2000; Ben-Shahar et al, 2004), the present study reveals that psychomotor sensitization is at best poorly correlated with the transition to and maintenance of escalated cocaine selfadministration. This interpretation is confirmed by data obtained during reinstatement testing. Cocaine-induced reinstatement of extinguished drug-seeking behavior was measured three times during the maintenance of cocaine self-administration, each time after $24 \mathrm{~h}$ of withdrawal. Regardless of the dose tested and of the reinstatement tests, cocaine failed to reinstate cocaine-seeking behavior in the majority of ShA rats, while it concurrently produced a significant dose-dependent stimulation of forward locomotion. Thus, although fully sensitized and despite having a long experience with cocaine self-administration, cocaine did not acquire significant motivational effects in most ShA rats. In contrast, in most LgA rats, cocaine acquired strong motivational properties, as evidenced during the three reinstatement tests. The prevalence of cocaine responders in the LgA group (about 80\%) was significantly greater than the prevalence of responders in the ShA group (about $30 \%$ on average). The different prevalence of cocaine responders between the ShA and LgA group was not due to any difference in cocaine-induced stimulation of locomotion (see Figure 5). Importantly, similar results were also obtained when rats were tested after 2 weeks of withdrawal, suggesting that the differences between ShA and LgA rats were persistent. This study demonstrates a dissociation between cocaine-induced psychomotor stimulation and cocaine-induced reinstatement during both early and late withdrawal.

The low prevalence of cocaine responders in the ShA condition shows that individuals can learn to take cocaine on a regular basis without necessarily becoming receptive to its motivational effects. This observation suggests that contrary to the psychomotor and rewarding effects of cocaine, its motivational effects are acquired, not unconditioned, effects. Previous reinstatement studies did not observe this phenomenon, however. Several procedural variables may explain this apparent discrepancy. First, in all previous studies except one (Deroche et al, 1999), daily access time to cocaine was longer than the minimum of the present study (ie $1 \mathrm{~h}$ ) and ranged between 2 and $6 \mathrm{~h}$ (eg de Wit and Stewart, 1981; Erb et al, 1996; De Vries et al, 1998; Lynch and Carroll, 2000; Lu et al, 2004; Fuchs et al, 2004; Schenk and Partridge 1999; Neisewander et al, 1996; Xi et al, 2004; Sutton et al, 2003; Dias et al, 2004). Thus, together with the present findings, this difference may point to the existence of some threshold duration below which most 
individuals readily learn to take cocaine without becoming responsive to its motivational effects and above which they begin to respond to these effects. Second, in most previous studies, different routes of administration were used between self-administration testing (i.v.) and reinstatement testing (i.p.), while in the present study, the same route of administration was used throughout the experiment. Since the route of administration (i.p. $v s$ i.v.) can profoundly alter the behavioral effects of cocaine (eg Nomikos and Spyraki, 1988; O'Dell et al, 1996), this factor could have contributed to the specific outcome of the present study. Finally, in most, although not all, previous studies, responding during reinstatement testing turned on the cue light that was paired with cocaine injections while in the present study, no contingent light cue was present during testing. Since stimulant drugs can dramatically increase both the unconditioned and conditioned rewarding effects of a light signal (eg Berlyne, 1969; Gomer and Jakubczak, 1974; Robbins, 1976; Robbins and Koob, 1978), this factor could also have contributed to the specific outcome of the present study. Regardless of the factors involved, this study nevertheless clearly shows that the rewarding and psychomotor effects of cocaine can be dissociated from its motivational effects in rats with restricted access to cocaine self-administration but not in rats that have developed compulsive cocaine use. Similar findings were recently obtained in rats with differential access to i.v. heroin selfadministration (Ahmed and Lenoir, in preparation).

As a whole, the present study shows that cocaine preferentially acquires stable motivational effects in individuals with escalating cocaine use, a conclusion consistent with other recent studies (Sutton et al, 2000; Mantsch et al, 2004), and therefore suggests that responsiveness to the motivational effects of the drug, not psychomotor sensitization, may represent a specific behavioral marker of drug addiction in the laboratory (Shaham et al, 2003; See et al, 2003; Weiss et al, 2001). We speculate that this differential responsiveness to the motivational effects of cocaine is somehow related to the profound decrease in brain reward function that was recently seen in LgA rats, but not in ShA rats, during escalation of cocaine selfadministration (Ahmed et al, 2002, 2003). By correcting or reducing this reward deficit, cocaine would secondarily acquire the ability to induce drug-seeking behavior, probably through a process of incentive learning not unlike that described recently by Dickinson and his colleagues (Dickinson and Balleine, 1994; Hutcheson et al, 2001). Future studies are needed to test this hypothesis.

\section{ACKNOWLEDGEMENTS}

This study was supported by grants from Université VictorSegalen Bordeaux 2, CNRS, MILDT and Région Aquitaine. We thank Laura Cameron and Magalie Lenoir for their help in conducting this study, Stéphane Lelgouach and Anne Fayoux for animal care, Pierre Gonzalez for technical assistance, Dr Luis Stinus for excellent laboratory management, and the reviewers for their constructive comments. We also thank the laboratories Sarget and Sanofi Synthelabo for their generous gifts of betadine and heparin, respectively.

\section{REFERENCES}

Ahmed SH, Kenny PJ, Koob GF, Markou A (2002). Neurobiological evidence for hedonic allostasis associated with escalating cocaine use. Nat Neurosci 5: 625-626.

Ahmed SH, Koob GF (1997). Cocaine-but not food-seeking behavior is reinstated by stress after extinction. Psychopharmacology 132: 289-295.

Ahmed SH, Koob GF (1998). Transition from moderate to excessive drug intake: change in hedonic set point. Science 282: 298-300.

Ahmed SH, Koob GF (1999). Long-lasting increase in the set point for cocaine self-administration after escalation in rats. Psychopharmacology 146: 303-312.

Ahmed SH, Koob GF (2005). Transition to drug addiction: a negative reinforcement model based on an allostatic decrease in reward function. Psychopharmacology 180: 473-490.

Ahmed SH, Lin D, Koob GF, Parsons LH (2003). Escalation of cocaine self-administration does not depend on altered cocaineinduced nucleus accumbens dopamine levels. J Neurochem 86: 102-113.

Ahmed SH, Lutjens R, van der Stap L, Lekic D, Romano-Spica V, Morales $\mathrm{M}$ et al (2005). Gene expression evidence for remodeling of lateral hypothalamic circuitry in cocaine addiction. Proc Natl Acad Sci USA (in press).

Ahmed SH, Stinus L, Le Moal M, Cador M (1993). Controlling interindividual differences in the unconditioned response to amphetamine in the study of environment-dependent sensitization. Behav Pharmacol 4: 355-365.

Ahmed SH, Walker JR, Koob GF (2000). Persistent increase in the motivation to take heroin in rats with a history of drug escalation. Neuropsychopharmacology 22: 413-421.

Barrett RJ, Caul WF, Smith RL (2004). Evidence for bidirectional cues as a function of time following treatment with amphetamine: implications for understanding tolerance and withdrawal. Pharmacol Biochem Behav 79: 761-771.

Ben-Shahar O, Ahmed SH, Koob GF, Ettenberg A (2004). The transition from controlled to compulsive drug use is associated with a loss of sensitization. Brain Res 995: 46-54.

Berlyne DE (1969). The reward value of light increment under supranormal and subnormal arousal. Can J Psychol 23: 11-23.

Bozarth MA, Wise RA (1985). Toxicity associated with long-term intravenous heroin and cocaine self-administration in the rat. $J$ Am Med Assoc 254: 81-83.

Caine SB, Lintz R, Koob GF (1993). Intravenous drug-selfadministration techniques in animals. In: Sahgal A (ed). Behavioural Neuroscience: A Practical Approach, Vol. 2, Oxford University Press: New York. pp 117-143.

De Vries TJ, Schoffelmeer AN, Binnekade R, Mulder AH, Vanderschuren LJ (1998). Drug-induced reinstatement of heroin- and cocaine-seeking behaviour following long-term extinction is associated with expression of behavioural sensitization. Eur J Neurosci 10: 3565-3571.

de Wit H, Stewart J (1981). Reinstatement of cocaine-reinforced responding in the rat. Psychopharmacology 75: 134-143.

Deneau G, Yanagita T, Seevers MH (1969). Self-administration of psychoactive substances by the monkey. Psychopharmacologia 16: $30-48$.

Deroche V, Le Moal M, Piazza PV (1999). Cocaine self-administration increases the incentive motivational properties of the drug in rats. Eur J Neurosci 11: 2731-2736.

Dias C, Lachize S, Boilet V, Huitelec E, Cador M (2004). Differential effects of dopaminergic agents on locomotor sensitisation and on the reinstatement of cocaine-seeking and food-seeking behaviour. Psychopharmacology 175: 414-427.

Dickinson A, Balleine BW (1994). Motivational control of goaldirected behavior. Anim Learn Behav 22: 1-18. 
Erb S, Shaham Y, Stewart J (1996). Stress reinstates cocaineseeking behavior after prolonged extinction and a drug-free period. Psychopharmacology 128: 408-412.

Fuchs RA, Evans KA, Parker MP, See RE (2004). Differential involvement of orbitofrontal cortex subregions in conditioned cue-induced and cocaine-primed reinstatement of cocaine seeking in rats. J Neurosci 24: 6600-6610.

Gomer FE, Jakubczak LF (1974). Dose-dependent selective facilitation of response-contingent light-onset behavior by D-amphetamine. Psychopharmacologia 34: 199-208.

Hooks MS, Duffy P, Striplin C, Kalivas PW (1994). Behavioral and neurochemical sensitization following cocaine self-administration. Psychopharmacology 115: 265-272.

Hutcheson DM, Everitt BJ, Robbins TW, Dickinson A (2001). The role of withdrawal in heroin addiction: enhances reward or promotes avoidance? Nat Neurosci 4: 943-947.

Johanson CE, Balster RL, Bonese K (1976). Self-administration of psychomotor stimulant drugs: the effects of unlimited access. Pharmacol Biochem Behav 4: 45-51.

Koob GF, Le Moal M (2001). Drug addiction, dysregulation of reward, and allostasis. Neuropsychopharmacology 24: 97-129.

Kuczenski R, Segal DS, Todd PK (1997). Behavioral sensitization and extracellular dopamine responses to amphetamine after various treatments. Psychopharmacology 134: 221-229.

Liu Y, Roberts DC, Morgan D (2005). Effects of extended-access self-administration and deprivation on breakpoints maintained by cocaine in rats. Psychopharmacology 179: 644-651.

Lu L, Grimm JW, Dempsey J, Shaham Y (2004). Cocaine seeking over extended withdrawal periods in rats: different time courses of responding induced by cocaine cues $v s$ cocaine priming over the first 6 months. Psychopharmacology 176: 101-108.

Lynch WJ, Carroll ME (2000). Reinstatement of cocaine selfadministration in rats: sex differences. Psychopharmacology 148: 196-200.

Lyon M, Robbins TW (1975). The action of central nervous system stimulant drugs: a general theory concerning amphetamine effects. In: Essman W, Valzelli L (eds). Current Developments in Psychopharmacology Vol. 2, Spectrum: New York. pp 79-163.

Mantsch JR, Ho A, Schlussman SD, Kreek MJ (2001). Predictable individual differences in the initiation of cocaine self-administration by rats under extended-access conditions are dosedependent. Psychopharmacology 157: 31-39.

Mantsch JR, Yuferov V, Mathieu-Kia AM, Ho A, Kreek MJ (2004). Effects of extended access to high $v s$ low cocaine doses on selfadministration, cocaine-induced reinstatement and brain mRNA levels in rats. Psychopharmacology 175: 26-36.

Meibohm B, Derendorf H (1997). Basic concepts of pharmacokinetic/pharmacodynamic (PK/PD) modelling. Int J Clin Pharmacol Ther 35: 401-413.

Neisewander JL, O'Dell LE, Tran-Nguyen LT, Castaneda E, Fuchs RA (1996). Dopamine overflow in the nucleus accumbens during extinction and reinstatement of cocaine self-administration behavior. Neuropsychopharmacology 15: 506-514.

Nomikos GG, Spyraki C (1988). Cocaine-induced place conditioning: importance of route of administration and other procedural variables. Psychopharmacology 94: 119-125.

O'Brien CP (2001). Drug addiction and drug abuse. In: Hardman JG, Limbird LE, Gilman AG (eds). Goodman and Gilman's the Pharmacological Basis of Therapeutics, 10th edn. McGraw-Hill: New York. pp 621-642.

O’Dell LE, Khroyan TV, Neisewander JL (1996). Dose-dependent characterization of the rewarding and stimulant properties of cocaine following intraperitoneal and intravenous administration in rats. Psychopharmacology 123: 144-153.
Paterson NE, Markou A (2003). Increased motivation for selfadministered cocaine after escalated cocaine intake. Neuroreport 14: 2229-2232.

Phillips AG, Di Ciano P (1996). Behavioral sensitization is induced by intravenous self-administration of cocaine by rats. Psychopharmacology 124: 279-281.

Robbins TW (1976). Relationship between reward-enhancing and stereotypical effects of psychomotor stimulant drugs. Nature 264: 57-59.

Robbins TW, Koob GF (1978). Pipradrol enhances reinforcing properties of stimuli paired with brain stimulation. Pharmacol Biochem Behav 8: 219-222.

Robinson TE, Berridge KC (1993). The neural basis of drug craving: an incentive-sensitization theory of addiction. Brain Res Rev 18: 247-291.

Roth ME, Carroll ME (2004). Sex differences in the escalation of intravenous cocaine intake following long- or short-access to cocaine self-administration. Pharmacol Biochem Behav 78: 199-207.

Schenk S, Partridge B (1999). Cocaine-seeking produced by experimenter-administered drug injections: dose-effect relationships in rats. Psychopharmacology 147: 285-290.

See RE, Fuchs RA, Ledford CC, McLaughlin J (2003). Drug addiction, relapse, and the amygdala. Ann NY Acad Sci 985: 294-307.

Shaham Y, Shalev U, Lu L, De Wit H, Stewart J (2003). The reinstatement model of drug relapse: history, methodology and major findings. Psychopharmacology 168: 3-20.

Stewart J, Vezina P (1991). Extinction procedures abolish conditioned stimulus control but spare sensitized responding to amphetamine. Behav Pharmacol 2: 65-71.

Sutton MA, Karanian DA, Self DW (2000). Factors that determine a propensity for cocaine-seeking behavior during abstinence in rats. Neuropsychopharmacology 22: 626-641.

Sutton MA, Schmidt EF, Choi KH, Schad CA, Whisler K, Simmons $\mathrm{D}$ et al (2003). Extinction-induced upregulation in AMPA receptors reduces cocaine-seeking behaviour. Nature 421: 70-75.

Tilson HA, Rech RH (1973). Conditioned drug effects and absence of tolerance to D-amphetamine induced motor activity. Pharmacol Biochem Behav 1: 149-153.

Vanderschuren LJ, Everitt BJ (2004). Drug seeking becomes compulsive after prolonged cocaine self-administration. Science 305: 1017-1019.

Weiss F, Ciccocioppo R, Parsons LH, Katner S, Liu X, Zorrilla EP et al (2001). Compulsive drug-seeking behavior and relapse. Neuroadaptation, stress, and conditioning factors. Ann NY Acad Sci 937: 1-26.

Wise RA, Bozarth MA (1987). A psychomotor stimulant theory of addiction. Psychol Rev 94: 469-492.

Wolffgramm J (1991). An ethopharmacological approach to the development of drug addiction. Neurosci Biobehav Rev 15: 515-519.

Xi ZX, Gilbert J, Campos AC, Kline N, Ashby Jr CR, Hagan JJ et al (2004). Blockade of mesolimbic dopamine D3 receptors inhibits stress-induced reinstatement of cocaine-seeking in rats. Psychopharmacology 176: 57-65.

Zapata A, Chefer VI, Ator R, Shippenberg TS, Rocha BA (2003). Behavioural sensitization and enhanced dopamine response in the nucleus accumbens after intravenous cocaine self-administration in mice. Eur J Neurosci 17: 590-596.

Zernig G, Wakonigg G, Madlung E, Haring C, Saria A (2004). Do vertical shifts in dose response rate-relationships in operant conditioning procedures indicate sensitization to drug wanting? Psychopharmacology 171: 349-351. 